Bryn Mawr College

Scholarship, Research, and Creative Work at Bryn Mawr College

Graduate School of Social Work and Social

Graduate School of Social Work and Social

Research Faculty Research and Scholarship

Research

2001

\title{
Client Participation: Central and Underinvestigated Elements of Intervention
}

Julia H. Littell

Bryn Mawr College, jlittell@brynmawr.edu

Leslie B. Alexander

Bryn Mawr College, lalexand@brynmawr.edu

William W. Reynolds

Let us know how access to this document benefits you.

Follow this and additional works at: http://repository.brynmawr.edu/gsswsr_pubs

Part of the Social Work Commons

\section{Custom Citation}

Littell, Julia H., Leslie B. Alexander, and William W. Reynolds. "Client Participation: Central and Underinvestigated Elements of Intervention." Social Service Review 75 (2001): 1-28.

This paper is posted at Scholarship, Research, and Creative Work at Bryn Mawr College. http://repository.brynmawr.edu/gsswsr_pubs/4

For more information, please contact repository@brynmawr.edu. 


\title{
Client Participation: Central and Underinvestigated Elements of Intervention
}

\author{
Julia H. Littell \\ Bryn Mawr College \\ Leslie B. Alexander \\ Bryn Mawr College \\ William W. Reynolds \\ Bryn Mawr College
}

\begin{abstract}
Although client participation is central to psychosocial interventions, most investigations conceptualize and measure participation in rather crude ways. This review suggests that essential elements of treatment participation are largely unknown, links between participation and outcomes are not clear, and most investigations of influences on withintreatment variations in participation are based on outdated causal models. Drawing on literature on health and mental health care, this article develops a comprehensive conceptual model of treatment participation. It proposes an agenda for future research aimed at understanding participation phenomena in various contexts.
\end{abstract}

Client participation problems - such as poor attendance, lack of engagement, early termination, noncompliance, and pro forma involvementabound in outpatient mental health (Kazdin, Holland, and Crowley 1997), substance abuse treatment (Szapocznik et al. 1988), child welfare (Famularo et al. 1989; Jellinek et al. 1992; Atkinson and Butler 1996), family support (Green, Johnson, and Rodgers 1998), welfare-to-work (Hasenfeld and Weaver 1996), and other social services. Variations in participation are linked to outcomes in health care (Blackwell 1997) 
and psychotherapy (Orlinsky, Grawe, and Parks 1994), but little is known about their effects in other settings, and their determinants are in dispute.

Most intervention research focuses on clients' problems, treatment methods, and outcomes. Client participation is an important, underinvestigated part of the treatment process. Better understanding of participation phenomena may lead to the development of more effective strategies for engaging clients in treatment and, if the treatment is effective, enhance outcomes. Exploration of the subjective meanings of participation to clients and clinicians may be useful for clinical purposes. Further intervention research could identify various strategies that clinicians and program administrators can use to improve client participation and outcomes related to participation. Once this knowledge is better developed, policy researchers might explore larger social and economic variables that support client participation in effective treatments.

In this article, we review existing conceptualizations and measures of treatment participation. We summarize empirical evidence on participation problems, its predictors, and its relationships to outcomes. We draw on the medical and psychotherapy literatures because they contain the most extensive research on treatment participation, but we do not undertake a comprehensive review of either. Rather, our purpose is to consider basic elements of treatment participation that may transcend modality and setting. ${ }^{1}$ We develop a conceptual model of factors that may affect treatment participation, offer some tentative implications for practice, and close by proposing an agenda for future research.

\section{Conceptual Views of Participation}

The literature on community-based mental health and social services often describes treatment participation in such vague and overlapping terms as engagement, involvement, compliance, and cooperation. Definitions and measures are inconsistent across studies. Different studies discuss client participation in strictly behavioral terms (e.g., attendance), as a complex cognitive-behavioral phenomenon (engagement), and in relational terms (collaboration). They use attendance as a surrogate for engagement (e.g., McKay, McCadam, and Gonzales 1996; Simpson, Joe, and Rowan-Szal 1997), adherence (Swanson, Pantalon, and Cohen 1999), compliance (Famularo et al. 1989; Butler, Radia, and Magnatta 1994; Atkinson and Butler 1996), and participation (Irueste-Montes and Montes 1988; Hu et al. 1997; McKay, McLellan et al. 1998; McLellan and Hunkeler 1998; Kazdin and Wassell 1999). Some studies focus on the frequency or duration of client participation in treatment, while others focus on more subjective, qualitative aspects.

Although the meanings of participation may be shaped by specific 
treatment regimens and goals, some common elements can be identified across settings. There are at least two participants in any psychosocial intervention, a helper and a client, whose roles and contributions differ. ${ }^{2}$ The helping relationship is nested in - and affected by-various other social systems and organizational contexts. In our view, the client role and boundaries of treatment participation are negotiated phenomena (i.e., client participation is shaped in dialogues between clinicians and clients), even in mandated treatment settings. Clients can participate in treatment through their involvement in problem identification, goal setting, and treatment planning; by attending sessions and carrying out recommendations; by providing feedback on intermediate outcomes; and by identifying new problems, strategies, and barriers to change.

Variations in client participation are most often discussed from the clinician's perspective and in terms of cooperation or resistance, as if these are two ends of a continuum (Gitterman 1983; Orlinsky et al. 1994). Studies rarely define these terms, which seem to tap several basic constructs. Participation can vary on at least two underlying dimensions: level of activity (ranging from passive to active) and valence (from negative to positive). Viewed orthogonally, these two dimensions form four quadrants (see fig. 1). From a clinician's perspective, attitudes and behaviors that are congruent with treatment goals and expectations are located at the positive end of the valence dimension, while those that diverge from clinical goals and expectations are at the negative end. Clinicians often view participation patterns that appear to be in the active-positive quadrant as ideal and describe these patterns as cooperation or compliance. They refer to perceived passive-negative participation as resistance. The other two quadrants may be characterized by clinicians as hostile or disruptive (active-negative) and acquiescent (passive-positive) participation. Of course, clients and clinicians may view the activity and valence dimensions differently. For instance, a client who suggests an alternative approach may see this as an active-positive effort, while the clinician might view it as resistance to treatment or hostility. Further, clients can participate in treatment in a variety of ways that are not necessarily consistent-from the helper's point of viewby complying with some aspects of treatment and not others, following recommendations while voicing opposition to them, or failing to meet agreed-on expectations. At the same time, any participation pattern may be internally consistent, logical, and desirable from the client's point of view (Donovan and Blake 1992; Morris and Schultz 1993).

To understand-and perhaps enhance - treatment participation, we think it best to view participation primarily from the client's perspective and recognize that this perspective is influenced by multiple factors within and outside of treatment. The most comprehensive, clientcentered explanation of participation in mental health services was developed by Alan Kazdin and colleagues, who identify several impor- 


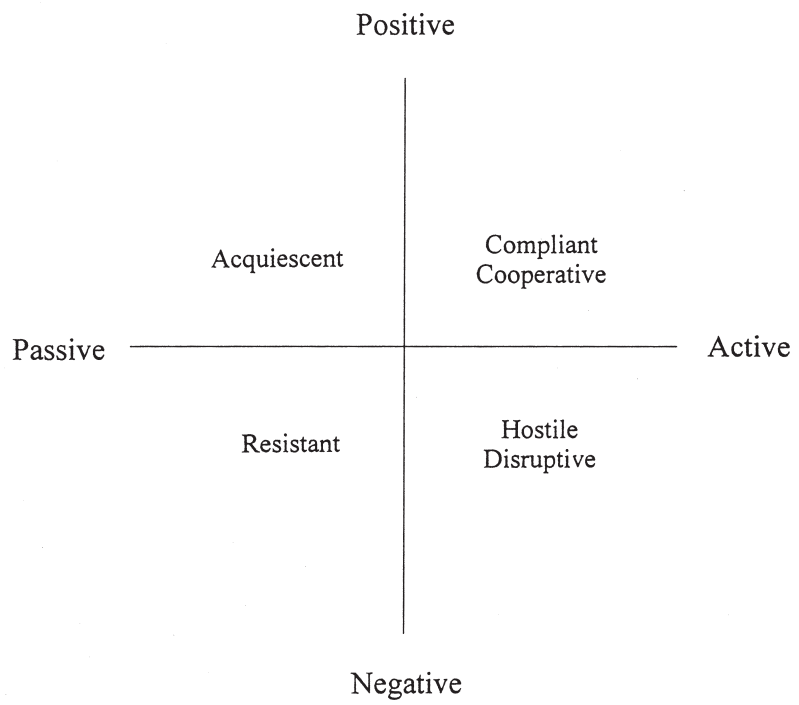

FIG. 1.-Qualities of client participation in treatment from a clinician's perspective

tant barriers to a client's treatment participation (Kazdin, Holland, and Crowley 1997; Kazdin, Holland, Crowley, and Breton 1997; Kazdin and Wassell 1999). Clients' perceptions of their problems and their treatment also are central in several models of medication compliance (Fenton, Blyler, and Heinssen 1997; Leventhal et al. 1997) and health services utilization (Andersen 1995). Taken together, these models suggest that treatment participation is dynamic, rather than static, and that it stems from decisions clients make based on their beliefs, goals, external constraints, and experiences in treatment, all of which are subject to the influence of significant others, clinicians, treatment settings, and larger social and cultural forces. Full client participation is a target and intermediate goal of effective interventions, not an immutable function of pretreatment client characteristics.

\section{Participation Measures}

Although there is little discussion in the literature about what treatment participation really means, the construct is measured in numerous ways. Examples are provided below to illustrate this diversity.

Dichotomous measures of treatment participation, commonly used in evaluation research, also are used in studies of factors associated with participation. Examples include the receipt of any service offered by an agency (e.g., Peled and Edleson 1998), receipt of any service after intake (e.g., McKay, McCadam, and Gonzales 1996), attrition or program completion (e.g., Danoff, Kemper, and Sherry 1994; Prinz and Miller 1994; Kazdin, Holland, and Crowley 1997; Kazdin, Holland, Crowley, 
and Breton 1997), retention for a minimum of 90 days (Hiller et al. 1998), and client acceptance or rejection of services (Murphy et al. 1991).

Studies of welfare-to-work programs employ a series of dichotomous variables to represent various aspects of participation. For example, Dale Weaver and Yeheskel Hasenfeld (1997) use three indicators of client noncompliance: failing to show up for program assignments, being "in conciliation" (the first formal step in trying to resolve noncompliant behavior), and experiencing financial sanctions (reduced welfare benefits). In another study, noncompliance is defined as rule evasion and uncooperative behavior (Hasenfeld and Weaver 1996). Eleven dichotomous measures of program participation (e.g., attended orientation, participated in any program activity, participated in specific activities, referred for sanction, and sanction imposed) are used in a study of two welfare-to-work case management models (Brock and Harknett 1998).

Attendance measures are becoming more common in studies of treatment participation, although there is little consistency among them. Some studies include simple frequencies of session attendance (e.g., Simpson, Joe, and Rowan-Szal 1997; Simpson, Joe, Rowan-Szal, and Greener 1997). Others measure attendance as the proportion of scheduled sessions that are not missed (Irueste-Montes and Montes 1988; McKay, Nudelman et al. 1996). Some studies use rates of canceled sessions, sessions missed without cancellation ("no shows"), and late arrivals per week in treatment (Kazdin, Holland, Crowley, and Breton 1997; Kazdin and Wassell 1999). Investigators also focus on attendance at initial sessions (McKay, Nudelman et al. [1996] examined attendance in the first three sessions) or within specific time intervals (e.g., Hu et al. [1997] uses four measures of treatment participation, defined as attendance for at least 1 day between intake and 1 month, 1-3 months, 3-6 months, and 6-12 months).

Two studies of court-ordered interventions in cases of child maltreatment use attendance measures to assess compliance-but they apply different criteria. Leslie Atkinson and Stephen Butler (1996) define compliance as a client's keeping at least 50 percent of scheduled appointments, while Butler et al. (1994) require at least 67 percent of appointments kept. A third study relies on therapist ratings of the adequacy of attendance when attendance data are missing, and it defines two levels of compliance: (1) attendance at a minimum of 50 percent of sessions or an attendance rating of "good" or "adequate" and (2) attendance at least 67 percent of sessions or a rating of "very good" or "excellent" attendance (Famularo et al. 1989).

Rudolf Moos and Melissa King's (1997) study of a community residential treatment program for substance abuse uses attendance ratings to assess participation in various activities. Staff rated the frequency of client participation in 31 activities in three areas: counseling and skills 
training (14 items), self-help activities (6 items), and social activities (11 items). Ratings were made at discharge on a four-point scale (not at all, 1-5 times, 6-10 times, 11 or more times).

Duration of treatment also is used to assess participation (Wierzbicki and Pekarik 1993). Three studies operationally define treatment participation as the number of days (Khoshnood, Kaplan, and Heimer 1995; Simpson, Joe, and Rowan-Szal 1997) or weeks (Connors et al. 1997; Kazdin, Holland, and Crowley 1997) between the first and last sessions attended, regardless of the frequency of attendance in between. Duration measures are sometimes capped at a certain point (e.g., up to 20 months in the study by Khoshnood et al. [1995]; up to 12 weeks in Connors et al. [1997]). Michael Wierzbicki and Gene Pekarik note that in psychotherapy, "both treatment completion and dropout can occur after virtually any number of sessions, making duration-based definitions of dropout conceptually distinct from definitions based on therapists' judgments of client termination status" (1993, p. 191).

Some researchers use a combination of measures that tap attendance, service provision, and duration. For example, Beth Green et al. (1998) operationalize engagement in family support programs as (1) the number of contacts per month, (2) the number of different types of services received, and (3) the length of time in the program (up to 1 year). Others treat such measures as characteristics of service delivery, not client participation (e.g., Brekke et al. 1997; Littell 1997; Brekke et al. 1999; Littell and Schuerman, in press). While the intensity, types, and duration of services are affected by program design and implementation, clients must be present and willing to participate if treatment is to be intensive or long term. Hence, these measures reflect both service delivery and participation.

Some studies employ ratings of certain qualities of participation, most often from the clinician's perspective. For instance, caseworker ratings of client cooperation (McCroskey and Meezan 1997) and other aspects of participation (Schuerman, Rzepnicki, and Littell 1994) are included in evaluations of family preservation services. June Thoburn, Ann Lewis, and David Shemmings (1995) identify three levels of family members' involvement in decisions and processes of child protection services: "partnership," the highest level, includes some joint decision making; "participation," the middle level, is not clearly defined; and the lower level, "involvement," means "being informed, consulted, and involved to some extent" (p. 167); the investigators classified a majority of the family members as not involved. In a study of methadone treatment, counselors provided ratings on 19 performance items; investigators thought some items reflected "early motivation and engagement," defined as "being dependable, well organized, cooperative, motivated, and attending counseling as scheduled" (Simpson, Joe, and Rowan-Szal 1997, p. 230). 
In a study of mandatory treatment for problem drinker-drivers (Snowden 1984), clients were asked to rate the extent to which they had (1) attended group sessions regularly and promptly, (2) explored and discussed their problem, (3) been hostile or disruptive, and (4) used others to avoid taking responsibility for their problems. They reported their answers to the group and made corrections to reflect group feedback. To assess client engagement in substance abuse treatment, Marilee Comfort and colleagues (Comfort et al. 2000) obtained client and staff ratings of client attendance, appearance, reasons for coming to treatment, urine screen results, openness to treatment, goal setting, goal attainment, need for encouragement, connections to staff, connections to other clients, utilization of information received in treatment, cooperation, constructive expression of feelings, and service utilization. Studies of psychotherapy include therapist, patient, or researcher ratings of client cooperation (vs. resistance); collaboration (vs. dependent or controlling behaviors); positive or negative affective responses; selfexploration; and personal engagement in the patient role (for a review see Orlinsky et al. [1994]).

Even in the medical field, where compliance is the subject of at least 14,000 English-language articles (Donovan 1995, cited in Fenton et al. 1997), definitions and measures vary across studies. Barry Blackwell (1997) provides a concise review of the many ways in which compliance is measured in medicine. Subjective methods of measurement include clinician ratings, collateral observations, patient interviews, and patient self-monitoring (e.g., diaries). Attempts to obtain objective measures of medication compliance rely on pill counts, biological methods (i.e., urine or blood tests), and medication event monitoring systems, in which time-recording microcircuitry is installed in pill containers, eyedroppers, or oxygen equipment to record medication events. Compliance is measured in categories (e.g., good, fair, poor, and nonadherent), by percentage of adherence to a regimen (e.g., medications, appointments, risk reduction behaviors), and with indices that include multiple behaviors.

A handful of studies examine treatment participation as a multidimensional construct. Meredith Hanson (1989) reports subjective, global assessments (ratings) of client participation from clinicians and clients, in addition to independent measures of length of stay in treatment (in weeks), dropout status, and intensity of involvement (number of visits divided by weeks in treatment). Ronald Prinz and Gloria Miller (1994) also use multiple measures of engagement in a study of two family treatment models: For each appointment, clinicians noted whether parents kept the appointment, canceled, or missed without cancellation; indicated whether parents completed homework; and rated each parent's in-session participation (on a five-point scale from very poor to good). In another study (of 30 clients in treatment for anxiety disorders), Ruth 
Nelson and Thomas Borkovec (1989) measured participation by therapist records of compliance with scheduling (late, no-shows, and rescheduled sessions) and homework assignments (relaxation practice and diary completion) and with client ratings of the credibility of the treatment rationale, satisfaction with services, expectation of improvement, engagement, and views of therapist and the therapeutic relationship. Scheduling and homework compliance measures are poorly intercorrelated, relatively unstable over time, and unrelated to other (client-rated) participation measures (Nelson and Borkovec 1989). Similarly, Jean Dumas and Jack Albin (1986) find low correlations between client attendance and compliance (i.e., homework completion) in a behavioral parent training program. In a study of family preservation services (Littell, in press), collaboration (i.e., involvement and agreement) with caseworkers in treatment planning is distinct from compliance (keeping scheduled appointments, successful task completion, and cooperation with caseworkers).

In sum, conceptualizations and measures of client participation are inconsistent across studies even within the same fields of practice. Most studies use a single measure of treatment participation. The most commonly used measures are (1) dichotomous indicators of program enrollment, service receipt, program completion, or status within a program; (2) quantitative measures of attendance or treatment duration; and (3) clinician ratings, usually of compliance or cooperation. The first two types of measures amount to little more than indicators of the client's physical presence and exposure to the intervention. However, as Carlo DiClemente and Sheryl Hughes observe, "not everyone who arrives for treatment actually shows up" (1990, p. 218). Some people "go through the motions" without real investment in treatment processes or goals. Research on easily measured aspects of participation far exceeds investigation of its more complex, less readily observable, but potentially more influential components. Although there is some evidence that participation is a multidimensional construct (Dumas and Albin 1986; Nelson and Borkovec 1989; Littell, in press), few studies treat it as such. Clinicians' ratings of client participation tend to be global and subjective; they do not provide information on actual involvement in various phases and processes of treatment. Few studies obtain client perspectives on participation in social services, and there is little understanding of the phenomenal meanings of participation to clients and clinicians (Atkinson and Butler 1996).

\section{Participation Problems}

In addition to the limitations of available measures, investigators derive data on client dropout rates, attendance, and participation in social services from program and clinic studies; there are no data from represen- 
tative samples. However incomplete, available data suggest that participation in public and quasi-public mental health and social services is often problematic in both voluntary and involuntary settings.

Attendance problems and high dropout rates are documented in outpatient mental health services (Wierzbicki and Pekarik 1993; Garfield 1994; McKay, Nudelman et al. 1996; Kazdin, Holland, and Crowley 1997), mandatory welfare-to-work programs (Hasenfeld and Weaver 1996; Weaver and Hasenfeld 1997), clinic-based parent education programs (Danoff et al. 1994), family support centers (Green, Johnson, and Rodgers 1998), and court-ordered treatment for parents in cases of child maltreatment (Famularo et al. 1989). In psychotherapy, a metanalysis of 125 studies reports a mean dropout rate of 47 percent (Wierzbicki and Pekarik 1993). Sol Garfield's (1994) review shows that 23-49 percent of outpatients did not attend a single therapy session after intake and two-thirds terminated before the tenth session. Hence, most clients receive less treatment than planned, even in brief treatment models (Beckham 1992).

Of the clients who do continue in clinic treatment, cancellations and no shows are common. In studies conducted by Kazdin and colleagues, patients missed an average of 30 percent (Kazdin and Wassell 1999) to 61 percent (Kazdin, Holland, Crowley, and Breton 1997) of scheduled sessions. Attendance problems arise even when treatment is mandated and the consequences of nonattendance may be severe, including permanent loss of child custody (Jellinek et al. 1992; Atkinson and Butler 1996). In one study of child maltreatment cases (Famularo et al. 1989), less than 40 percent of parents attended court-ordered treatment regularly (at least 67 percent of the time).

Beyond attendance, compliance with treatment regimens is often difficult to obtain in either voluntary or involuntary settings. High rates of noncompliance with medical prescriptions are documented in health care settings among patients who seek treatment, even when noncompliance will result in immediate and severe consequences, such as blindness (Vincent 1971, cited in Rooney 1992). According to Blackwell, "overall estimates are that half of outpatients and a quarter of inpatients default significantly from prescribed regimens" in medicine (Blackwell 1998, p. 627; also see Cramer and Rosenheck 1998).

Dropout, poor attendance, and noncompliance are not random events. In outpatient mental health services, client dropout rates are consistently related to low income, low levels of education, and ethnic minority status (Wierzbicki and Pekarik 1993; Garfield 1994). Early termination and noncompliance also are linked to a mismatch between clients' perceptions of their needs and of the relevance or demands of treatment (Kazdin, Holland, and Crowley 1997), discontinuity between outcomes valued by clients and clinicians (Morris and Schulz 1993), and clients' negative expectations about treatment (Grilo et al. 1998). Be- 
cause treatment regimens vary in complexity, clients achieve some types of compliance and behavioral change more readily than others. For example, "medication compliance is more readily achieved than modification in lifestyle" (Blackwell 1997, p. 10).

High dropout rates, poor attendance, and noncompliance are costly in both economic and human terms. Some portion of clinicians' time (at intake and in missed appointments) is wasted. This results in increased service costs and the occupation of treatment slots that might be used by others (Kazdin, Holland, and Crowley 1997; Kazdin, Holland, Crowley, and Breton 1997). To compensate for no-shows, some clinical settings overschedule appointments, but when this practice results in delayed appointments, it might exacerbate client participation problems. If the client misses out on an effective intervention, then participation problems may be costly in human terms as well, for "without adequate exposure to treatment services - either medical or behavioral - therapeutic benefits cannot accrue" (Simpson, Joe, and Rowan-Szal 1997, p. 233). However, "adequate exposure" is not well-defined, especially in psychosocial services.

\section{Treatment Participation and Outcomes}

There is evidence that links some aspects of client participation in some interventions to some outcomes. The prevailing notion in psychotherapy is that "the quality of the patient's participation in therapy stands out as the most important determinant of outcome" (Orlinsky et al. 1994, p. 361). However, the assumption that there is a causal relationship between participation and outcomes has not been carefully tested. Before reviewing relevant empirical evidence, we identify other plausible explanations for the correlation between participation and outcomes.

\section{Rival Explanations}

Selection bias.-Clients are not randomly assigned to different levels of participation, and the choices they and others make about the extent of their involvement in treatment are not random, either. These choices are likely to be affected by a host of factors, including severity of presenting problems (Salzer, Bickman, and Lambert 1999), desire for help (Simpson, Joe, and Rowan-Szal 1997), perceived barriers to treatment (Kazdin, Holland, Crowley, and Breton 1997), efficacy expectations (Grilo et al. 1998), and ethnicity and socioeconomic status (Wierzbicki and Pekarik 1993; Garfield 1994). Thus, it may be the factors associated with different levels of participation - rather than participation per se-that are responsible for variations in outcomes. If so, associations between participation and outcomes may be artifacts of selection bias. Controls for selection bias are lacking in most studies of treatment participation.

Nonlinear, reciprocal relationships. - Most client participation studies are 
based on unidirectional, linear models of causality. That is, participation is thought to cause the effects (outcomes), not vice versa, and more participation is expected to result in greater gains. However, relationships between participation and outcomes may be reciprocal (Littell, in press). Early benefits-such as symptom relief-may encourage clients to persist, while lack of improvement or negative side effects may lead them to withdraw from treatment. The relationship between participation and outcomes is probably nonlinear. While some participation may be better than none, there may be limits to the amount of change that can be obtained with incremental increases in levels of participation at the high end. Clients may encounter ceiling effects when their initial problems are not severe (and there is little room for improvement) or when treatment efficacy is limited.

Attribution bias. - Caseworkers and clients may attribute positive outcomes to the treatment or treatment participation when results are really caused by external factors. In hindsight, caseworkers may view successful clients as more involved in treatment than they really were. On the other hand, they may rate cooperative clients as more successful than others (a "halo" effect), even if the clients' outcomes are quite similar. For example, Jacquelyn McCroskey and William Meezan (1997) find that caseworker reports of parental cooperation were related to caseworker-rated improvements in two out of six areas of family functioning, even though client reports indicated that there were no significant changes in family functioning during the intervention. Alan Kazdin, Lisa Holland, and Michael Crowley (1997) note that clinicians' knowledge of who dropped out might influence their ratings of perceived barriers to participation. Thus, clinicians' knowledge of outcomes may affect ratings of client participation and vice versa.

Underlying mechanisms. - Investigators and clinicians often assume that active participation augments treatment effects by increasing exposure to the intervention; this is thought to result in a client's more rapid cognitive and behavioral change, which leads to better outcomes. Other causal chains are possible, however. The quality of client participation may affect professional recommendations and decisions, which in turn produce certain outcomes. In child welfare, for example, parental noncompliance is a potent predictor of casework and judicial decisions related to child custody (Jellinek et al. 1992; Atkinson and Butler 1996). Moos reports that clients who participated more intensively in substance abuse treatment "were more likely to complete the program, to engender staff confidence in their recovery, and to be discharged to a stable residence" (Moos 1998, p. 17). In this example, staff confidence may have been responsible for the link between participation and outcomes. Robert Hatcher finds that "what appears to therapists as the patient's steadfast and confident investment" in treatment is linked to therapists' sense of progress in therapy $(1999$, p. 418). While more frequent or 
more positive participation may predict better outcomes, we should not assume that participation is the primary cause of cognitive or behavioral change.

\section{Empirical Evidence}

With these caveats in mind, there is some evidence that more frequent and consistent participation is associated with better outcomes in health care (Blackwell 1997), psychotherapy (Garfield 1994; Orlinsky et al. 1994), substance abuse treatment (e.g., Simpson, Joe, and Rowan-Szal 1997; Griffith et al. 1998; Simpson et al. 1999), and child welfare (Jellinek et al. 1992; Atkinson and Butler 1996; Littell, in press). In medicine, overall estimates indicate that up to 1 in 10 hospital and 1 in 4 nursing home admissions are a direct result of a patient's failure to adhere to prescribed regimens (Blackwell 1998). Yet there is not a one-toone relationship between compliance and outcomes. As Blackwell (1998, p. 628) observes, " 80 percent compliance may result in weight gain on a diet while the same degree of compliance will attain good blood pressure control on an antihypertensive regimen." Overall, more than half of the studies of medication compliance fail to demonstrate a positive relationship between compliance and the outcome measured (Blackwell 1997). This may be due to the use of faulty measures in some studies, but it is likely that certain kinds of compliance (e.g., pill taking vs. clinic attendance) affect some outcomes and not others. Similarly, research on the effects of participation in mental health and child welfare services yields mixed results (Orlinsky et al. 1994; Littell, in press).

Until very recently, the notion that more treatment is better was a wellaccepted truism. In the psychotherapy literature, where the dose-effect relationship was studied most systematically, this assumption has not held up. Newer metanalytic studies indicate that there is no overall linear relationship between the number of sessions and clinical outcomes (Salzer et al. 1999). Clients who remain in psychotherapy make consistent gains through the first six months, but this upward curve is followed by a plateau indicating that there are diminished gains afterward (for a concise review, see Lambert and Bergin [1994]). In a large study of outpatient mental health services for children, Mark Salzer et al. (1999) find that the dose effect is fully explained by the impact of initial problem severity on both dose and outcome: greater severity is related to longer treatment and more room for improvement. Findings in other fields are mixed. The duration and intensity of home-based services are not strong predictors of outcomes in child welfare (Littell 1997; Littell and Schuerman, in press), but they are positively associated with outcomes of community support programs for persons with schizophrenia spectrum disorders (Brekke et al. 1997; Brekke et al. 1999). In substance abuse treatment, better outcomes are associated with regular attendance and 
longer treatment duration (e.g., Simpson, Joe, and Rowan-Szal 1997; Griffith et al. 1998; Simpson et al. 1999) and with the frequency of within-treatment activities (Moos and King 1997; Moos 1998).

A few studies suggest that the quality, rather than frequency or duration, of client participation matters. In psychotherapy, ratings of client cooperation, collaboration, and engagement in the patient role are associated with more favorable outcomes in about two-thirds of the findings reviewed by David Orlinsky et al. (1994). These findings are fairly consistent, regardless of whether ratings (of treatment participation or outcome) were made by clinicians, patients, or independent observers. Based on a small sample, Ruth Nelson and Thomas Borkovec's findings suggest that "quantitative degrees of compliance with scheduling and homework, as opposed to qualitative aspects of such compliance, are relatively unrelated to the client's satisfaction with therapy and the therapeutic relationship or to outcome" (1989, p. 162). Mary O'Brien and Keith Petrie (1996) find that high levels of patient participation (defined as the number of disclosures and questions) in medical consultations do not always reflect cohesive or constructive participation; rather, high participation often reflects distress and difficulty communicating with the physician. In a program for problem drinker-drivers, Lonnie Snowdon (1984) finds that the quality of participation in weekly sessions (measured by client ratings of their attendance, self-exploration, disruptiveness, and blaming and manipulation) is independent of client variables at intake (alcoholism, psychopathology, and social background) and that hostility and disruption are associated with greater success. According to Snowden (1984, p. 70), "it may be that participation, sometimes positive and sometimes negative is what unlocks for clients the possibility of constructively changing their behavior."

In sum, findings regarding the effects of variations in treatment participation are mixed and open to a variety of interpretations. While frequency measures are most often used, more subjective and qualitative aspects of participation may be as important.

\section{Influences on Participation}

In research on psychotherapy, investigators examined a range of preintervention variables at the client, clinician, modality, setting, and environmental levels along with within-treatment interactional processes (Howard et al. 1996). In most instances, the relationship of these variables to treatment participation, however measured, is hit or miss and more empirically than conceptually driven. Most studies focus on factors associated with attrition or continuation, rather than more subtle aspects of within-treatment participation. Findings across studies are somewhat inconsistent because of the use of different definitions (e.g., of dropout or continuation), diverse client groups and treatment procedures, and 
different data collection techniques (Armbruster and Fallon 1994; Garfield 1994).

In contrast, the medical literature covers a wider array of compliance behaviors, including clinic attendance, filling prescriptions, and adherence to recommendations. But like research on psychotherapy, emphasis is on predictors that are most easily measured (demographic variables and type of illness) and on patient rather than physician characteristics and behaviors. Findings are not generalizable across behaviors, conditions, or settings. For instance, clinic attendance and medication compliance appear to have different determinants, and factors that affect compliance in one situation may fail to do so in another (Blackwell 1997, p. 9). Howard Leventhal and colleagues suggest that this complexity should not be equated with chaos. Apparent inconsistencies might be resolved by identifying contextual or moderator variables that affect participation, but this can only be accomplished by viewing empirical findings within a strong theoretical framework (Leventhal et al. 1997).

Here we develop a conceptual model of factors that may affect client participation in a variety of treatment settings, drawing on a self-regulation model of medication compliance (Leventhal et al. 1997), the work of Alan Kazdin and colleagues in children's mental health services, a model of treatment participation in intensive family preservation services (Littell and Tajima 2000), and empirical findings in several fields of practice. At present, we view participation as a set of behaviors that can be characterized in terms of activity levels and valence; other useful conceptualizations of participation are likely to emerge as work in this area progresses. Participation is influenced by a number of factors outside of and within treatment. Below, we discuss components of our current model; shown in figure 2.

\section{Pretreatment and External Factors}

Client characteristics.-Most explanations for variations in treatment participation center on client characteristics at intake (Moore-Kirkland 1981; Gitterman 1983; Miller 1985; Walitzer, Derman, and Connors 1999) and extant research reflects this orientation. As indicated above, there is evidence that low socioeconomic status is related to treatment dropout (Wierzbicki and Pekarik 1993; Armbruster and Fallon 1994; Garfield 1994; Kazdin, Holland, and Crowley 1997; Grilo et al. 1998). Kazdin and colleagues report that other client background factorssuch as being from a minority group, single parenthood, early childbearing, harsh child-rearing practices, and a history of antisocial behavior in childhood - also predict dropout. At the same time, they note that these "variables of convenience" are easily obtained and encompass broad characteristics "that neither shed light on the possible mechanisms involved in dropping out nor suggest guidelines for where, when, and how 


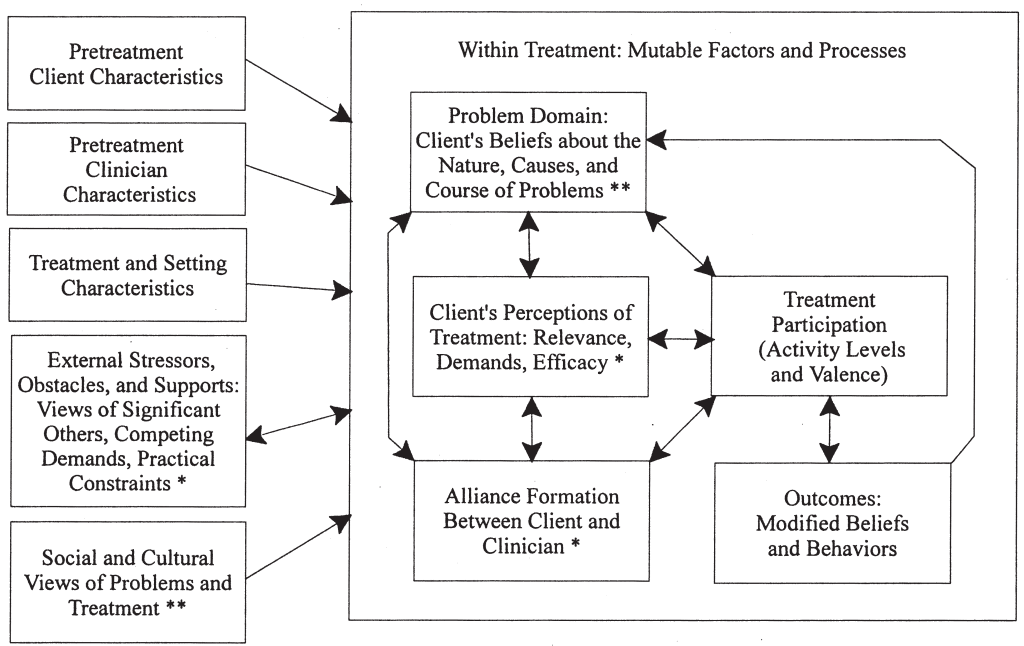

Fig. 2.-A conceptual model of treatment participation. Note.- $*$ = from the barriers to treatment participation model (Kazdin and Wassell 1999); $* *=$ from the selfregulatory systems model of medication compliance (Leventhal et al. 1997).

to intervene to prevent dropping out" (Kazdin, Holland, and Crowley 1997 , p. 453). So not only do these variables predict a small proportion of the variance in treatment participation (Garfield 1994), many cannot be affected by clinical interventions alone.

The complexity, chronicity, and severity of presenting problems may predict initial ease or difficulty of client participation in treatment, either because these problems impair client functioning or because they are not adequately addressed in a particular setting. For example, anxiety and substance abuse are related to noncompliance in medicine (Blackwell 1998), and substance abuse, interpersonal violence, and mental health problems are linked to parental noncompliance in cases of child maltreatment (Famularo et al. 1989; Murphy et al. 1991; Butler et al. 1994; Littell and Tajima 2000). A number of pretreatment client conditions may predict a smoother treatment process, including some level of friendliness, likableness, impulse control, self-discipline, and some internalization of blame (Morey 1999). While these indicators may be "a reasonable starting point for estimating the degree of difficulty likely to be encountered as part of the treatment process" (Morey 1999, p. 1099), they are not immutable. Similarly, although much has been made of the importance of pretreatment motivation or readiness for change, these are not good predictors of treatment attendance, duration, or program completion (see Isenhart 1994; Cady et al. 1996; Hutchison 1996; and Willoughby and Edens 1996). Although initial motivation can be high, change can be slow and difficult, especially in relation to problems that are complex, chronic, and severe. Further, other fac- 
tors - including the type of intervention, clinician responsiveness, and social and economic resources - may affect and alter motivation throughout treatment.

Clinician characteristics. - Clinician's attributes and attitudes have been neglected in the study of treatment participation (Garfield 1997), although there is reason to believe that certain characteristics of the helper are related to clients' responses to treatment (Beutler, Machado, and Neufeldt 1994). For example, caseworkers' beliefs about the nature and etiology of clients' problems appear to have some bearing on their casework activities (Kim 1993), and a deficit orientation (i.e., the belief that clients have few strengths) is associated with low levels of parental collaboration and compliance in intensive family preservation services (Littell and Tajima 2000). Similarly, parent-blaming, a problem identified among some professionals in children's mental health services (Johnson, Cournoyer, and Fisher 1994; Johnson and Renaud 1997; Alexander and Dore 1999), may impede participation. One cannot assume that clinicians perform equally well with all clients. There is some evidence that interactions between client characteristics and clinicians' prior training, experience, and attitudes toward clients account for some variations in treatment participation, although these effects are not particularly potent (Littell and Tajima 2000).

Treatment and setting characteristics.-Interventions in mental health, child welfare, and related fields take place in a variety of settings (including offices, homes, hospitals, and community organizations), under different auspices (public and private services), and with varying degrees of structure (e.g., in the number, frequency, and length of contacts) and coerciveness, all of which may singly and in combination affect perceptions of the treatment and participation in it. Program-level variations in the structure and emphasis of service delivery may account for some variations in treatment participation (Littell and Tajima 2000). While court orders and coercive referrals appear to have mixed effects on participation (Wolfe et al. 1980; Irueste-Montes and Montes 1988; Famularo et al. 1989; Armbruster and Fallon 1994; Hiller et al. 1998; Littell and Tajima 2000), case management practices and the strategies used to gain compliance may have more potent effects. For example, in mandatory welfare-to-work programs, Yeheskel Hasenfeld and Dale Weaver (1996) suggest that noncompliance will be high when constraints or coercion are used, if clients are not closely monitored. "In contrast, persuasion will generate a high level of compliance, and inducements [rewards] will produce moderate rates of compliance" (p. 238). An emphasis on clients' choices and on providing an exit option (Weaver and Hasenfeld 1997), and a focus on personal attention versus formal penalties (Riccio and Hasenfeld 1996) also are associated with better compliance.

The climate of social service organizations and the working conditions they provide for helpers may influence both the service delivery process 
and clients' responses to intervention (Glisson and Hemmelgarn 1998). In mandatory welfare-to-work programs such organizational characteristics as nonstigmatizing ideologies, goals that stress development of longterm skills, a people-changing (vs. people-processing) service technology, and professional treatment of clients are associated with better compliance (Hasenfeld and Weaver 1996).

External stressors, obstacles, and supports.-Clients' conflicts with significant others about treatment, competing demands (e.g., work and childcare responsibilities), and practical constraints (e.g., transportation and scheduling problems) are among the barriers to treatment participation identified by Kazdin and colleagues. Whether identified by the parent or clinician, these external stressors and obstacles are related to clients' dropping out of community-based children's mental health services (Kazdin, Holland, and Crowley 1997). The influence of significant others also accounts for some variation in compliance in medicine (Blackwell 1997), and a few studies document the impact of family support on participation in clinic and community-based services (Armbruster and Fallon 1994; Littell and Tajima 2000). Unlike other factors that are external to treatment, some obstacles and supports can be modified through intervention.

Social and cultural influences.-Social and cultural factors affect the construction and expression of presenting problems, beliefs about their causes and potential cures, and views of various types of formal intervention. Few studies examine social and cultural influences on within-treatment variations in participation.

\section{Within-Treatment Factors}

In the self-regulation model of medication compliance, people are seen as active problem-solvers, trying to make sense of their world and searching for ways of controlling and adapting to it (Leventhal et al. 1997). Clients' beliefs about the nature, cause, progression, and consequences of the presenting problem may or may not be accurate but are thought to be powerful influences on behavior. In this model, "compliance is a product of the meanings the individual assigns to his or her . . problem and the perceived relevance and/or reasonableness of the recommended treatment procedures to the defined problem. This 'problem domain' contains the key meanings defining the individual's phenomenological view of his/her illness and treatment. The problem domain is nested within a series of overlapping social contexts such as that between patient and practitioner, that between the treatment dyad and the family, and of both to media and larger culture" (Leventhal et al. 1997, p. 31).

Problem domain.-The problem domain includes attributes or beliefs about the identity (symptoms and name) of the problem, its causes, time 
frame (for the development and duration of the problem), consequences, and control. "These attributes are working hypotheses, rather than fixed beliefs, and vary across persons and over time for the same person" (Leventhal et al. 1997, p. 23). These hypotheses can be explored and altered in treatment.

Client perceptions of treatment.-As mentioned earlier, client perceptions of treatment as demanding, not relevant to the problem, and not likely to be helpful are important barriers to participation (Kazdin and Wassell 1999). These barriers "do not overlap with and are not explained by family, parent, and child factors that also relate to dropping out of treatment" (Kazdin, Holland, Crowley, and Breton 1997, p. 1057). Whether rated by the clinician or client, these negative perceptions of treatment predict dropout, duration of treatment, and rates of canceled sessions and no-shows in community-based children's mental health services. Of the barriers to treatment participation identified by Kazdin and colleagues, a client's perception that treatment is irrelevant is the strongest predictor of dropout (Kazdin, Holland, and Crowley 1997).

Alliance formation.-In addition to the prediction of a range of subjective and objective client outcomes, alliance formation (a positive working relationship) between the clinician and client predicts continuation in psychotherapy (Connors et al. 1997), community-based mental health services (Kazdin, Holland, and Crowley 1997), substance abuse treatment (Simpson, Joe, and Rowan-Szal 1997; Simpson, Joe, Rowan-Szal, and Greener 1997), and compliance with medical regimens (Blackwell 1998). The alliance is a relational context within which client perceptions of problems and treatment can be examined and shaped (Dore and Alexander 1996; Alexander and Dore 1999). The alliance has both direct and mediating effects on client outcomes (Horvath and Greenberg 1994). In this context, treatment participation is likely to be enhanced by involving clients in treatment planning (Littell, in press), providing constructive feedback (Miller 1985), and conveying hope that the situation can be improved (Frank and Frank 1991; Kinney, Haapala, and Booth 1991; Howard et al. 1993). Although most alliance research is conducted in structured, clinic settings and in dyads, alliance formation may be equally important in other contexts and configurations (Dore and Alexander 1996), including work with families (Pinsof 1994; Alexander and Dore 1999). Recent evidence suggests that the quality and strength of the alliance may ebb and flow during the course of interventions (Safran and Muran 2000). These so-called ruptures and repairs in the alliance may relate to whether clients participate at all (or drop-out) and to the quality of participation in treatment.

Outcomes. - To the extent that clients' beliefs and behaviors are modified in treatment, outcomes are likely to affect perceived needs and subsequent service utilization (Andersen 1995). Early outcomes, such as symptom reduction or increased discomfort, may affect further participation. 


\section{Interventions to Enhance Participation}

Based on a metanalysis of 153 studies, Debra Roter and colleagues find that educational, behavioral, and affectively focused interventions improve compliance with medical regimens. Although no single strategy has clear advantages over another, interventions that combine these three components are more effective than those with a single focus (Roter et al. 1998). Outside of medicine, there are relatively few tests of efforts to enhance participation. Mary McKay and colleagues increased attendance at initial appointments using telephone engagement interviews (McKay, McCadam, and Gonzales 1996; McKay, Stoewe et al. 1998) and specialized training in engagement interviewing that focused on role induction, relationship formation, problem identification, and problem solving (McKay, Nudelman et al. 1996). José Szapocznik and colleagues developed and tested a strategic structural family systems intervention designed to overcome initial resistance to treatment (Szapocznik et al. 1988). Using the diagnostic, joining, and restructuring techniques of brief strategic family therapy, they increased attendance at intake and improved retention of hard-to-reach families in treatment (Santisteban et al. 1996).

\section{Implications for Practice}

Given what little is known about client participation in treatment, we offer some tentative implications for practice. First, clinicians and program administrators should identify and monitor indicators of client participation in a particular treatment and setting. Attendance and continuation may be important, but these are not sufficient to distinguish active participants from those who are merely going through the motions. Attention should be paid to the subjective meanings of client participation to clients and clinicians and to qualities of client participation that may relate to outcomes.

Second, more participation is not necessarily better. Like dose effects, the relationship between client participation (however conceptualized or measured) and outcomes is probably not linear. When there is a good fit between the client's needs and treatment plans, there may be an optimal level of participation (in terms of activity level, valence, frequency, and duration) for that client, with little to be gained from even greater participation. Optimal levels of participation may vary across clients, treatment modalities, and settings. Until more is known about this topic, clinicians and clients should consider how much (and what kind of) client participation is sufficient to achieve specific treatment goals.

As indicated above, there is some evidence that client participation can be improved by clinical interventions. Rather than focusing on pretreatment client characteristics, as most investigators have done, clinicians should attend to their own influence and effects of the treatment 
setting on client participation. We encourage clinicians to view client participation as an outgrowth of interactions between clinicians and clients, which are shaped by larger social, cultural, and economic factors (see fig. 2). Client participation may be closely linked to the alliance between a client and clinician. Finally, thoughtful reflections on client participation from clinical perspectives (e.g., what participation entails, how it develops, what affects it, and how it relates to outcomes) ought to be disseminated to enhance knowledge in this area.

\section{A Research Agenda}

To better understand treatment processes and outcomes, we need to (1) develop more refined measures of client participation, (2) employ more sophisticated analyses of relationships between participation and outcome measures, and (3) further investigate factors that affect important components of participation. Here we provide directions for future work in these areas.

\section{Participation Measures}

Blackwell (1997, p. 6) notes that "in the [medication] compliance field ... simple measures are not accurate and accurate measures are not simple." Since no method is without drawbacks, participation is not a simple phenomenon, and its essential elements are unknown, we need multiple methods and multiple measures of treatment participation. Measures of various components of participation can be developed in relation to the specific characteristics and demands of a treatment setting, with an eye to elements that may be transferrable across settings and modalities. Until the processes and outcomes of participation are better understood, careful assessments will (1) include both objective and subjective indicators of participation; (2) tap affective, cognitive, and behavioral dimensions of participation; (3) obtain multiple perspectives; and (4) measure participation at several points in time during the intervention.

Objective measures of activity levels might include the number of client contacts by clinician (by phone or in person), the percentage of appointments kept by the client, and the number and types of tasks completed. Subjective assessments are equally important because behaviors (especially those that can be quantified) are not necessarily representative of clients' cognitive and affective responses to treatment. We suggest that it is important to measure both activity and valence, that is, the extent to which clients' responses are congruent with (or divergent from) clinicians' treatment goals and expectations.

At a minimum, participation data should be gathered from both the client and the clinician. When applicable, multiple clinicians and mul- 
tiple clients (e.g., family members) may provide different and useful perspectives on treatment participation. Some lack of congruence between helpers' and clients' perceptions of client participation is to be expected, as this has been documented in several studies in the medical field (Fenton et al. 1997; Goldberg, Cohen, and Rubin 1998), where "both patients and providers are prone to overestimate compliance and physicians are particularly inaccurate at predicting it" (Blackwell 1998, p. 628). Service providers usually have a better sense of program expectations than clients do, and thus they are in a better position to make judgments about compliance. These judgments may be biased (e.g., by "halo" effects), but they are important in themselves, because they can affect outcomes (Jellinek et al. 1992; Atkinson and Butler 1996; Littell, in press). Clients' perceptions of their own responses to treatment are also inherently important - and these may be biased as well. Clients' accounts of their involvement in treatment are likely to be inflated when there are real or perceived adverse consequences for nonparticipation, as there are in some mandated services. The tendency to give socially desirable answers may make it difficult to distinguish rote responses from real involvement, but that distinction should be a goal of further research and can be attained by including social desirability measures in treatment participation studies (see Reynolds 1982).

Since the nature and extent of participation may change during the course of an intervention, it is useful to obtain repeated measures (both objective and subjective) of client participation. These might be linked to specified phases of treatment or administered on a regular (weekly or monthly) basis. Several authors say that participation measures are reasonable, empirically based indicators of individual and program performance (e.g., Simpson, Joe, and Rowan-Szal 1997). As performance indicators, participation measures can be monitored over time. This facilitates identification of cases or situations in which midcourse corrections are needed.

\section{Outcome Studies}

Much more work is needed to understand relationships between treatment participation and outcomes (Kazdin, Holland, Crowley, and Breton 1997). More refined participation measures would permit identification of elements of participation that are essential-individually or jointly-to achieve desired outcomes. These essential elements (or sets of elements) may vary across treatment settings, populations, and outcomes. As in the dose-effect studies in psychotherapy, gains may increase with greater levels of participation in some aspects of treatment and not others, with diminished returns after a certain point.

When causal relationships between participation measures and outcomes are examined, researchers must consider several rival explana- 
tions. Credible studies will consider selection effects, attribution bias, and social desirability bias. Statistical controls for selection bias are available (cf. Heckman 1978, 1979; Heckman and MaCurdy 1985; Heckman and Robb 1985), albeit imperfect (Berry 1984). Attribution bias can be avoided by obtaining independent measures of participation and outcomes (avoiding common method error variance), and social desirability bias can be measured (Reynolds 1982). Investigators should consider whether there are nonlinear and reciprocal relationships between participation and outcome measures (cf. Asher 1983; Berry 1984; Pindyck and Rubinfeld 1991). Explication of underlying mechanisms that link participation and outcomes will enhance understanding of treatment processes (Littell, in press).

\section{Predictors of Participation}

Several conceptual models of treatment participation and medication compliance provide useful directions for future research on the multiple influences on participation phenomena. Blackwell (1997) notes that the self-regulatory systems model is comprehensive but difficult to apply because of its multivariate and transactional nature; the same could be said about our model of treatment participation. However, to the extent that they capture the multiple influences and processes that affect participation, the strength of these models may lie in their complexity. It is clear that older and simpler models - especially those that view participation as a function of immutable client characteristics-are inadequate. A strong conceptual framework is vital to guide further inquiry in this area. Following such a model, multivariate analysis can be used to tease out complex, mediated, nonlinear, and reciprocal relationships among predictors (and outcomes) of various aspects of participation.

Outside of medicine, there has been little systematic investigation of factors that account for within-treatment variations in client participation. Of particular interest are mutable factors, those that might be modified to enhance participation in effective treatments. Especially ripe for further investigation are clinician, service delivery, organizational, and environmental influences on client participation. Hierarchical linear models can be used to capture influences of variables at several system levels (e.g., client, clinician, and organization) and cross-level interactions (cf. Bryk and Raudenbush 1992; Littell and Tajima 2000). These and other random regression models can be used to study timevarying measures of treatment participation and covariates. It is possible that some common factors - such as alliance formation and the barriers identified by Kazdin and his colleagues - will be predictive of variations in some aspects of participation across treatment settings and modalities, while other predictors of participation will be specific to client populations, intervention methods, and treatment settings. Experimental stud- 
ies of interventions to enhance client participation (such as those conducted by Szapoznik et al. 1988 and McKay, Stowe et al. 1998) are also needed.

\section{Conclusions}

Given the central role of client participation in treatment, it is remarkable that so little attention has been paid to this process. Our review of the literature indicates that participation problems-such as poor attendance, lack of engagement, early termination, noncompliance, and pro forma involvement-abound in mental health, substance abuse treatment, child welfare, family support, welfare-to-work, and other social services. In these fields, the study of client participation is erratic rather than systematic. In particular, within-treatment variations in participation are not carefully studied. Most measures-usually of attendance or continuation - are too crude to capture subtle and perhaps more essential elements of client participation. More sophisticated conceptualizations and measures of participation are needed, for treatment participation is not a single phenomenon, but a complex set of attitudes and behaviors that vary along several dimensions and can change over time. We identify two underlying dimensions of client participation (activity level and valence), but others might be proposed. Further work is needed to identify essential elements of client participation within - and perhaps across - treatment settings.

Most conceptual and empirical models of relationships between treatment participation and outcomes are based on simple, unidirectional casual models. We identify several threats to the validity of these models and better ways to address these issues in future research. Sound theories of participation processes and sophisticated analytic techniques are required to cope with selection, attribution, and social desirability biases and to model reciprocal and nonlinear relationships between participation and outcome measures. Although there is some evidence that participation is a product of complex interactions between clients, helpers, and cultural and environmental factors (Littell and Tajima 2000), studies emphasize the effects on participation of conveniently measured, pretreatment client characteristics rather than more mutable influences. Drawing on models of medication compliance, barriers to participation, and empirical work in several fields, we present a conceptual model of influences on client participation. We hope that this model will stimulate and (perhaps) guide further investigation of treatment participation processes. Our model should be tested, informed, and refined by subsequent investigations. In the future, emphasis should be placed on identification of mutable predictors of treatment participation at the client, helper, alliance, and organizational levels. Better understanding of these factors might be used to 
enhance the relevance and effectiveness of interventions, particularly in populations that are not adequately served at present.

\section{References}

Alexander, Leslie B., and Martha M. Dore. 1999. "Making the Parents as Partners Principle a Reality: The Role of the Alliance." Journal of Child and Family Studies 8:255-70.

Andersen, Ronald M. 1995. "Revisiting the Behavioral Model and Access to Medical Care: Does It Matter?" Journal of Health and Social Behavior 36:1-10.

Armbruster, Paula, and Theodore Fallon. 1994. "Clinical, Sociodemographic, and Systems Risk Factors for Attrition in a Children's Mental Health Clinic." American Journal of Orthopsychiatry 64:577-85.

Asher, Herbert B. 1983. Causal Modeling. 2d ed. Newbury Park, Calif.: Sage.

Atkinson, Leslie, and Stephen Butler. 1996. "Court-Ordered Assessment: Impact of Maternal Noncompliance in Child Maltreatment Cases." Child Abuse and Neglect 20:185-90.

Beckham, Edward E. 1992. "Predicting Patient Dropout in Psychotherapy." Psychotherapy 29:177-82.

Berry, William D. 1984. Nonrecursive Causal Models. Newbury Park, Calif.: Sage.

Beutler, Larry E., Paulo P. P. Machado, and Susan Allstetter Neufeldt. 1994. "Therapist Variables." Pp. 229-69 in Handbook of Psychotherapy and Behavior Change, edited by Allen E. Bergin and Sol L. Garfield. 4th ed. New York: Wiley.

Blackwell, Barry. 1997. "From Compliance to Alliance: A Quarter Century of Research." Pp. 1-15 in Treatment Compliance and the Therapeutic Alliance, edited by Barry Blackwell. Amsterdam: Harwood Academic.

_. 1998. "Compliance." Pp. 625-38 in Handbook of Psychosomatic Medicine, edited by Giovanni A. Fava and Hellmuth Freyberger. Madison, Conn.: International Universities Press.

Brekke, John S., Mark Ansel, Jeffrey Long, Elizabeth Slade, and Marvin Weinstein. 1999. "Intensity and Continuity of Services and Functional Outcomes in the Rehabilitation of Persons with Schizophrenia." Psychiatric Services 50:248-56.

Brekke, John S., Jeffrey D. Long, Noel Nesbitt, and Eugene Sobel. 1997. "The Impact of Service Characteristics on Functional Outcomes from Community Support Programs for Persons with Schizophrenia: A Growth Curve Analysis." Journal of Consulting and Clinical Psychology 65:464-75.

Brock, Thomas, and Kristen Harknett. 1998. "A Comparison of Two Welfare-to-Work Case Management Models.” Social Service Review 72:493-520.

Bryk, Anthony S., and Stephen W. Raudenbush. 1992. Hierarchical Linear Models: Applications and Data Analysis Methods. Newbury Park, Calif.: Sage.

Butler, Stephen M., Nick Radia, and Michael Magnatta. 1994. "Maternal Compliance to Court-Ordered Assessment in Cases of Child Maltreatment." Child Abuse and Neglect 18: 203-11.

Cady, Mary E., Ken C. Winters, Danielle A. Jordan, Kenneth B. Solberg, and Randy Stinchfield. 1996. "Motivation to Change as a Predictor of Treatment Outcome for Adolescent Substance Abusers." Journal of Child and Adolescent Substance Abuse 5:73-91.

Comfort, Marilee, Alan Sockloff, Joan Loverro, and Karol Kaltenbach. 2000. "Multiple Predictors of Substance Abusing Women's Treatment and Life Outcomes: A Prospective Longitudinal Study.” Manuscript. Philadelphia: Comfort Consults.

Connors, Gerard J., Kathleen M. Carroll, Carlo C. DiClemente, Richard Longabaugh, and Dennis M. Donovan. 1997. "The Therapeutic Alliance and Its Relationship to Alcoholism Treatment Participation and Outcome." Journal of Consulting and Clinical Psychology $65: 588-98$.

Cramer, Joyce A., and Robert Rosenheck. 1998. "Compliance with Medication Regimens for Mental and Physical Disorders." Psychiatric Services 49:196-201.

Danoff, Nancy L., Kathi J. Kemper, and Bettylou Sherry. 1994. "Risk Factors for Dropping Out of a Parenting Education Program." Child Abuse and Neglect 8:599-606.

DiClemente, Carlo C., and Sheryl O. Hughes. 1990. "Stages of Change Profiles in Outpatient Alcoholism Treatment." Journal of Substance Abuse 2:217-35.

Donovan, Jenny L. "Patient Decision Making: The Missing Ingredient in Compliance Research." International Journal of Technology Assessment in Health Care 11:43-55. 
Donovan, Jenny L., and David R. Blake. 1992. "Patient Non-compliance: Deviance or Reasoned Decision Making?” Social Science and Medicine 34:507-13.

Dore, Martha M., and Leslie B. Alexander. 1996. "Preserving Families at Risk of Child Abuse and Neglect: The Role of the Helping Alliance." Child Abuse and Neglect 20:34961.

Dumas, Jean E., and Jack B. Albin. 1986. "Parent Training Outcome: Does Active Parental Involvement Matter?” Behavioral Research and Therapy 24:227-30.

Famularo, Richard, Robert Kinscherff, Doris Bunshaft, Gayl Spivak, and Terrence Fenton. 1989. "Parental Compliance to Court-Ordered Treatment Interventions in Cases of Child Maltreatment." Child Abuse and Neglect 13:507-14.

Farmer, Elizabeth M. Z., Dalene K. Stangl, Barbara J. Burns, E. Jane Costello, and Adrian Angold. 1999. "Use, Persistence, and Intensity: Patterns of Care for Children's Mental Health across One Year." Community Mental Health Journal 35:31-46.

Fenton, Wayne S., Crystal R. Blyler, and Robert K. Heinssen. 1997. "Determinants of Medication Compliance in Schizophrenia: Empirical and Clinical Findings." Schizophrenia Bulletin 23:637-51.

Frank, Jerome D., and Julia B. Frank. 1991. Persuasion and Healing: A Comparative Study of Psychotherapy. Baltimore, Md.: Johns Hopkins University Press.

Garfield, Sol L. 1994. "Research on Client Variables in Psychotherapy." Pp. 190-228 in Handbook of Psychotherapy and Behavior Change, edited by Allen E. Bergin and Sol L. Garfield. 4th ed. New York: Wiley.

_ 1997. "The Therapist as a Neglected Variable in Psychotherapy Research." Clinical Psychology: Science and Practice 4:40-43.

Gitterman, Alex. 1983. "Uses of Resistance: A Transactional View." Social Work 28:127-31.

Glisson, Charles, and Anthony Hemmelgarn. 1998. "The Effects of Organizational Climate and Interorganizational Coordination on the Quality and Outcomes of Children's Service Systems." Child Abuse and Neglect 22:401-21.

Goldberg, Albert I., Gilat Cohen, and Ami-Hai E. Rubin. 1998. "Physician Assessments of Patient Compliance with Medical Treatment." Social Science and Medicine 47:1873-76.

Green, Beth L., Sharon A. Johnson, and Angela Rodgers. 1998. "Understanding Patterns of Service Delivery and Participation in Community-Based Family Support Programs." Children's Services: Social Policy, Research, and Practice 2:1-22.

Griffith, James D., Danica K. Knight, George W. Joe, and D. Dwayne Simpson. 1998. "Implications of Family and Peer Relations for Treatment Engagement and Follow-Up Outcomes: An Integrative Model." Psychology of Addictive Behaviors 12:113-26.

Grilo, Carlos M., Roy Money, David H. Barlow, Andrew W. Goddard, Jack M. Gorman, Stefan G. Hofmann, Laszlo A. Papp, M. Katherine Shear, and Scott W. Woods. 1998. "Pretreatment Patient Factors Predicting Attrition from a Multicenter Randomized Controlled Treatment Study for Panic Disorder." Comprehensive Psychiatry 39:323-32.

Hanson, Meredith. 1989. "Involving Clients in Outpatient Treatment: Implications for Social Work Practice." Alcoholism Treatment Quarterly 5:209-20.

Hasenfeld, Yeheskel, and Dale Weaver. 1996. "Enforcement, Compliance, and Disputes in Welfare-to-Work Programs." Social Service Review 70:235-56.

Hatcher, Robert L. 1999. "Therapists' Views of Treatment Alliance and Collaboration in Therapy." Psychotherapy Research 9:405-23.

Heckman, James J. 1978. "Dummy Endogenous Variables in a Simultaneous Equation System." Econometrica 46:931-61.

- "Sample Selection Bias as a Specification Error." Econometrica 47:153-61.

Heckman, James J., and Thomas E. MaCurdy. 1985. "A Simultaneous Equations Linear Probability Model." Canadian Journal of Economics 28:28-37.

Heckman, James J., and Richard Robb, Jr. 1985. "Alternative Methods for Evaluating the Impact of Interventions." Pp. 156-245 in Longitudinal Analysis of Labor Market Data, edited by James Heckman and Burton Singer. Cambridge: Cambridge University Press.

Hiller, Matthew L., Kevin Knight, Kirk M. Broome, and D. Dwayne Simpson. 1998. "Legal Pressure and Treatment Retention in a National Sample of Long-Term Residential Programs." Criminal Justice and Behavior 25:463-81.

Horvath, Adam O., and Leslie S. Greenberg. 1994. The Working Alliance: Theory, Research, and Practice. New York: Wiley.

Howard, Kenneth I., Thomas A. Cornille, John S. Lyons, John T. Vessey, Robert J. Lueger, and Stephen M. Saunders. 1996. "Patterns of Mental Health Service Utilization." Archives of General Psychiatry 53:696-703. 
Howard, Kenneth I., Robert J. Lueger, Michael S. Maling, and Zora Martinovich. 1993. "A Phase Model of Psychotherapy: Causal Mediation of Outcome." Journal of Consulting and Clinical Psychology 61:678-85.

$\mathrm{Hu}$, Teh-wei., Enid M. Hunkeler, Constance Weisner, Elizabeth Li, Devin Kalile Grayson, James Westphal, and A. Thomas McLellan. 1997. "Treatment Participation and Outcome among Problem Drinkers in a Managed Care Alcohol Outpatient Treatment Program." Journal of Mental Health Administration 24:23-34.

Hutchison, Linda. 1996. "Application of the Transtheoretical Model's Stages and Processes of Change in Predicting Treatment Attrition among Substance Abusers." Ph.D. diss. University of Memphis.

Irueste-Montes, Ana Maria, and Francisco Montes. 1988. "Court-Ordered vs. Voluntary Treatment of Abusive and Neglectful Parents." Child Abuse and Neglect 12:33-39.

Isenhart, Carl E. 1994. "Motivational Subtypes in an Inpatient Sample of Substance Abusers." Addictive Behavior 19:463-75.

Jellinek, Michael S., J. Michael Murphy, Francis Poitrast, Dorothy Quinn, Sandra J. Bishop, and Marilyn Goshko. 1992. "Serious Child Maltreatment in Massachusetts: The Course of 206 Children through the Courts." Child Abuse and Neglect 16:179-85.

Johnson, Harriette C., David E. Cournoyer, and Gene A. Fisher. 1994. "Measuring Worker Cognitions about Parents of Children with Mental and Emotional Disabilities." Journal of Emotional and Behavioral Disorders 1:99-108.

Johnson, Harriette C., and Edwin F. Renaud. 1997. "Professional Beliefs about Parents of Children with Mental and Emotional Disabilities." Journal of Emotional and Behavioral Disorders 5: 149-61.

Kazdin, Alan E., Lisa Holland, and Michael Crowley. 1997. "Family Experience of Barriers to Treatment and Premature Termination from Child Therapy." Journal of Consulting and Clinical Psychology 65:453-63.

Kazdin, Alan E., Lisa Holland, Michael Crowley, and Susan Breton. 1997. "Barriers to Treatment Participation Scale: Evaluation and Validation in the Context of Child Outpatient Treatment." Journal of Child Psychology and Psychiatry 38:1051-62.

Kazdin, Alan E., and Gloria Wassell. 1999. "Barriers to Treatment Participation and Therapeutic Change among Children Referred for Conduct Disorder." Journal of Clinical Child Psychology 28:160-72.

Khoshnood, Kaveh, Edward H. Kaplan, and Robert Heimer. 1995. "Dropouts or Drop-ins? Client Retention and Participation in New Haven's Needle Exchange Program." Public Health Reports 110:462-66.

Kim, Hye Lan. 1993. "The Influence of Caseworkers' Orientations toward Child Maltreating Families on Casework Activities and Case Outcomes." Ph.D. diss. University of Chicago.

Kinney, Jill, David Haapala, and Charlotte Booth. 1991. Keeping Families Together: The Homebuilders Model. New York: Aldine de Gruyter.

Lambert, Michael J., and Allen E. Bergin. 1994. "The Effectiveness of Psychotherapy." Pp. 143-89 in Handbook of Psychotherapy and Behavior Change, edited by Allen E. Bergin and Sol L. Garfield. New York: Wiley.

Leventhal, Howard, Jennifer F. Lambert, Michael Diefenbach, and Elaine A. Leventhal. 1997. "From Compliance to Social-Self-Regulation: Models of the Compliance Process." Pp. 17-33 in Treatment Compliance and the Therapeutic Alliance, edited by Barry Blackwell. Amsterdam: Harwood Academic.

Littell, Julia H. 1997. "Effects of the Duration, Intensity, and Breadth of Family Preservation Services: A New Analysis of Data from the Illinois Family First Experiment." Children and Youth Services Review 19:19-41.

- In press. "Client Participation and Outcomes of Intensive Family Preservation Services." Social Work Research.

Littell, Julia H., and John R. Schuerman. In press. "What Works Best for Whom? A Closer Look at Intensive Family Preservation Services." Children and Youth Services Review.

Littell, Julia H., and Emiko A. Tajima. 2000. "A Multilevel Model of Client Participation in Intensive Family Preservation Services." Social Service Review 74:405-35.

McCroskey, Jacquelyn, and William Meezan. 1997. Family Preservation and Family Functioning. Washington, D.C.: Child Welfare League of America.

McKay, James R., A. Thomas McLellan, Arthur I. Alterman, John S. Cacciola, Megan J. Rutherford, and Charles P. O'Brien. 1998. "Predictors of Participation in Aftercare Sessions 
and Self-Help Groups Following Completion of Intensive Outpatient Treatment for Substance Abuse." Journal of Studies on Alcohol 59:152-62.

McKay, Mary McKernan, Kathleen McCadam, and J. Jude Gonzales, 1996. "Addressing the Barriers to Mental Health Services for Inner City Children and Their Caretakers." Community Mental Health Journal 32:353-61.

McKay, Mary McKernan, Ruth Nudelman, Kathleen McCadam, and Jude Gonzales. 1996. "Evaluating a Social Work Engagement Approach to Involving Inner-City Children and Their Families in Mental Health Care." Research on Social Work Practice 6:462-72.

McKay, Mary McKernan, Judith Stoewe, Kathleen McCadam, and Jude Gonzales. 1998. "Increasing Access to Child Mental Health Services for Urban Children and Their Caregivers." Health and Social Work 23:9-15.

McLellan, A. Thomas, and Enid Hunkeler. 1998. "Patient Satisfaction and Outcomes in Alcohol and Drug Abuse Treatment." Psychiatric Services 49:573-75.

Miller, William R. 1985. "Motivation for Treatment: A Review with Special Emphasis on Alcoholism." Psychological Bulletin 98:84-107.

Moore-Kirkland, Janet. 1981. "Mobilizing Motivation: From Theory to Practice." Pp. 27-54 in Promoting Competence in Clients: A New/Old Approach to Social Work Practice, edited by Anthony N. Maluccio. New York: Free Press.

Moos, Rudolf H. 1998. Community Residential Facilities for VA Substance Abuse Patients: An Evaluation of the Contract Program for Veterans with Alcohol and Drug Dependence Disorders. Palo Alto, Calif.: Department of Veterans Affairs Health Care System.

Moos, Rudolf H., and Melissa J. King. 1997. "Participation in Community Residential Treatment and Substance Abuse Patients' Outcomes at Discharge." Journal of Substance Abuse Treatment 14:71-80.

Morey, Leslie C. 1999. "Personality Assessment Inventory." Pp. 1083-1121 in The Use of Psychological Testing for Treatment Planning and Outcomes Assessment, edited by Mark E. Maruish. 2d ed. Mahweh, N.J.: Lawrence Erlbaum.

Morris, Lisa Stockwell, and Richard M. Schultz. 1993. "Medication Compliance: The Patient's Perspective." Clinical Therapeutics 15:593-606.

Murphy, J. Michael, Michael Jellinek, Dorothy Quinn, Gene Smith, Francis G. Poitrast, and Marilyn Goshko. 1991. "Substance Abuse and Serious Child Maltreatment: Prevalence, Risk, and Outcome in a Court Sample." Child Abuse and Neglect 15:197-211.

Nelson, Ruth A., and Thomas D. Borkovec. 1989. "Relationship of Client Participation to Psychotherapy." Journal of Behavior Therapy and Experimental Psychiatry 20:155-62.

O'Brien, Mary, and Keith J. Petrie. 1996. "Examining Patient Participation in Medical Consultations: A Combined Quantitative and Qualitative Approach." Psychology and Health $11: 871-90$.

Orlinsky, David E., Klaus Grawe, and Barbara K. Parks. 1994. "Process and Outcome in Psychotherapy-Noch Einmal." Chapter 7 in Handbook of Psychotherapy and Behavior Change, edited by Allen E. Bergin and Sol L. Garfield. 4th ed. New York: Wiley.

Peled, Einat, and Jeffrey L. Edleson. 1998. "Predicting Children's Domestic Violence Service Participation and Completion." Research on Social Work Practice 8:698-712.

Pindyck, Robert S., and Daniel L. Rubinfeld. 1991. Econometric Models and EconomicForecasts. 3d ed. New York: McGraw-Hill.

Pinsof, William. 1994. "An Integrative Systems Perspective on the Therapeutic Alliance: Theoretical, Clinical, and Research Implications." Pp. 173-95 in The Working Alliance: Theory, Research, and Practice, edited by Adam O. Horvath and Leslie S. Greenberg. New York: Wiley.

Prinz, Ronald J., and Gloria E. Miller. 1994. "Family-Based Treatment for Childhood Antisocial Behavior: Experimental Influences on Dropout and Engagement." Journal of Consulting and Clinical Psychology 62:645-50.

Reynolds, William M. 1982. "Development of Reliable and Valid Short Forms of the Marlowe-Crowne Social Desirability Scale." Journal of Clinical Psychology 38:119-25.

Riccio, James, and Yeheskel Hasenfeld. 1996. "Enforcing a Participation Mandate in a Welfare-to-Work Program.” Social Service Review 70:516 - 42.

Rooney, Ronald H. 1992. Strategies for Work with Involuntary Clients. New York: Columbia University Press.

Roter, Debra L., Judith A. Hall, Rolande Mersica, Beth Nordstrom, Deborah Cretin, and Bonnie Svarstad. 1998. "Effectiveness of Interventions to Improve Patient Compliance: A Meta-analysis." Medical Care 36:1138-61. 
Safran, Jeremy D., and J. Christopher Muran. 2000. Negotiating the Therapeutic Alliance: A Relational Treatment Guide. New York: Guilford.

Salzer, Mark S., Leonard Bickman, and E. Warren Lambert. 1999. "Dose-Effect Relationship in Children's Psychotherapy Services." Journal of Consulting and Clinical Psychology 67:228-38.

Santisteban, Daniel A., José Szapocznik, Angel Perez-Vidal, William M. Kurtines, Edward J. Murray, and Arthur LaPerriere. 1996. "Efficacy of Intervention for Engaging Youth and Families into Treatment and Some Variables That May Contribute to Differential Effectiveness." Journal of Family Psychology 10:35-44.

Schuerman, John R., Tina L. Rzepnicki, and Julia H. Littell. 1994. Putting Families First: An Experiment in Family Preservation. New York: Aldine de Gruyter.

Simpson, D. D., G. W. Joe, B. W. Fletcher, R. I. Hubbard, and M. D. Anglin. 1999. "A National Evaluation of Treatment Outcomes for Cocaine Dependence." Archives of General Psychiatry 56:507-13.

Simpson, D. Dwayne, George W. Joe, and Grace A. Rowan-Szal. 1997. "Drug Abuse Treatment Retention and Process Effects on Follow-Up Outcomes." Drug and Alcohol Dependence 47:227-35.

Simpson, D. Dwayne, George W. Joe, Grace A. Rowan-Szal, and Jack M. Greener. 1997. "Drug Abuse Treatment Process Components That Improve Retention." Journal of Substance Abuse Treatment 14:565-72.

Snowden, Lonnie R. 1984. "Treatment Participation and Outcome in a Program for Problem Drinker-Drivers." Evaluation and Program Planning 7:65-71.

- 1999. "African American Service Use for Mental Health Problems." Journal of Community Psychology 27:303-13.

Swanson, Arthur J., Michael V. Pantalon, and Kenneth R. Cohen. 1999. "Motivational Interviewing and Treatment Adherence among Psychiatric and Dually Diagnosed Patients." Journal of Nervous and Mental Disease 187:630-35.

Szapocznik, José, Angel Perez-Vidal, Andrew L. Brickman, Franklin H. Foote, Daniel Santisteban, Olga Hervis, and William M. Kurtines. 1988. "Engaging Adolescent Drug Abusers and Their Families into Treatment: A Strategic Structural Systems Approach." Journal of Consulting and Clinical Psychology 56:552-57.

Thoburn, June, Ann Lewis, and David Shemmings. 1995. "Family Participation in Child Protection." Child Abuse Review 4:161-71.

Vincent, P. 1971. "Factors Influencing Patient Noncompliance: A Theoretical Approach." Nursing Research 20:509-16.

Walitzer, Kimberly S., Kurt R. Derman, and Gerard J. Connors. 1999. "Strategies for Preparing Clients for Treatment: A Review.” Behavior Modification 23:129-51.

Weaver, Dale, and Yeheskel Hasenfeld. 1997. "Case Management Practices, Participants' Responses, and Compliance in Welfare-to-Work Programs." Social Work Research 21 :92100 .

Wierzbicki, Michael, and Gene Pekarik. 1993. "A Meta-analysis of Psychotherapy Dropout." Professional Psychology: Research and Practice 24:190-95.

Willoughby, Frederick W., and John F. Edens. 1996. "Construct Validity and Predictive Utility of the Stages of Change Scale for Alcoholics." Journal of Substance Abuse 8:27591.

Wolfe, David, John Aragona, Keith Kaufman, and Jack Sandler. 1980. "The Importance of Adjudication in the Treatment of Child Abusers: Some Preliminary Findings." Child Abuse and Neglect 4:127-35.

\section{Notes}

1. Issues of service utilization (i.e., whether or not people seek or receive treatment) are not considered here. For reviews on service utilization in mental health, see Howard et al. (1996); Farmer et al. (1999); and Snowden (1999).

2. We use the terms "helper" and "clinician" to refer to caseworkers, therapists, and others who provide services directly to clients. 